\title{
Quality of Life as a Factor of Socio-Ecological and Economic Assessment
}

\section{Garifova L.F.}

\author{
Kazan Federal University, Kazan, 420008, Russia
}

Kundakchyan R.M.

Kazan Federal University, Kazan, 420008, Russia

E-mail address: rezstat@yandex.ru

\section{Doi:10.5901/mjss.2014.v5n18p95}

\section{Abstract}

In this article, the author substantiates the need for the social factor for integrated assessment, problems and prospects of development of the territory. Negative tendencies showing demographic crisis in the region. Special attention is paid to the scientific background and quantitative estimate of this index calculated for some municipal districts of the republic of Tatarstan. The offered methodology of calculation of integral indicator of population welfare will allow to estimate the level of socialeconomic, ecological welfare of population who lives on the territory of this district taking into account the influence of institutional factors. The obtained integrated figures can be used for estimate of efficiency of municipal districts' activities in the sphere of social-economic and ecological policy.

Keywords: quality of life, index of population welfare, ecology, risk factors, quality of life environment, environment.

\section{Introduction}

During the last three decades rise of interest to the problem of quality of life is connected with perception by the society global contemporary problems, international regulatory requirements of European Community countries concerning optimization of socio-economic situation, modernization of economic potential on the basis of innovative technologies and the aim of Russia to become the full member of WTO.

In the available Russian and foreign literature the research of problems of quality of life, especially on the regional level, are of episodic nature. There are very few research works of this problem (devoted to the studies of ecologicaleconomic aspects of quality of life, health and welfare) in the form of complex multidimensional parameter.

In these conditions necessity of quantitative estimate of quality of life appeared; it allows to obtain data concerning different conditions of life of members of society. However, the data obtained cannot always become the basis for management of quality of life and different methodological approaches are often used. In order to eliminate this problem and to obtain reliable, comparable parametric figures the authors of the article introduced the term "index of population welfare" and the model of its definition.

In connection with the above matter, in this work we make the attempt of ecological-economic explanation of the index of population welfare, in the basis of which there is the conception of life welfare, which allows to estimate not only population health, but welfare of life of population on this territory taking into account influence of risk factors of different intensity as well.

\section{Literature Review}

For a long time improvement of life quality has been an apparent aim or an implicit goal for some people, communities, peoples and countries of the world, quality of life is considered as multidimensional conception which contains interaction of objective and subjective elements [2].

During the last 30 years in editions of Social Indicators of Research a lot of authors described great variety of ways to present multidimensional space of different conceptions of quality of life according to some definite one-dimension scale, such reductions are meant for simplification of complex idea of static time series and they are actually tied to their simplification [6]. A large number of villages, cities, districts and regions initiated their own local project indicators, actually, social project indicators on local level, these project indicators presuppose the use of subjective, as well as 
objective index numbers related to social, economic and ecological population welfare [6]. Social index numbers "...are used for monitoring of social system and they help to determine the changes in management to be made in the process of social changes" [4].

Now ecological and system-forming components are priority directions of the study of social-ecological-economic systems. Social-ecological-economic system is interconnected combination of elements of natural, production, demographic and social character which function on some territories [12]. Environmental economics and ecological economics have common purpose: to understand interaction "individual-economics-environment" in order to redirect economics into direction of sustained development [11]. All this allows to consider environment as space where people and harmonic condition of environment are of principal importance [9].

During the last 10 years many countries dramatically increased amount of quantitative and qualitative data, consequently, the researchers came back to the problem of development of new indexes of quality of life and other indicators of efficiency of economic development [6]. Thus, there will be competition between the use of different indicators in order to determine which indicators and indexes can be used to estimate theories, hypothesis, models of social, ecological and economic changes of life quality of population in the best way in the sphere of social-ecologicaleconomic indicators of research of quality of life.

\section{Research}

The authors chose the zone of activities of oil exploration and production sector as the research object; this zone was divided - according to the exploration level - into three zones. The first zone is the territory of the beginning of commercial exploitation of oil recovery (Aznakayevsky, Almetyevsky, Bavlinsky, Bugulminsky, Leninogorsky, Cheremshansky, Yutazinsky regions). The second zone is the territory of Aksubayevsky, Zainsky, Yelabuzhsky, Muslyumovsky, Novosheshminsky, Nurlatsky, Sarmanovsky municipal districts where oil recovery started later, with appearance of ecologically safe technologies, but, nevertheless, their introduction was rather difficult because of necessity of maximum oil recovery in the years of developed socialism. On the territory of the third zone (Agryzsky, Aktanyshsky, Alekseevsky, Mendeleevsky, Menzelinsky, Mamadyshsky, Chistopolsky regions) commercial oil exploitation started at the end of the XX century, when ecologically safe technologies were developed, long-term plans for protection of components of ecosystem were explained, optimum size of oil recovery was determined, and this allowed to reduce the negative impact on quality of life environment and human population to the maximum.

According to the research data $[5 ; 13]$, concentration of pollutants in atmospheric air (hydrogen sulphide, sulfur dioxide) sometimes exceeded allowable level 5-10 times, even in cities and villages. The opinion about inevitability of pollution of atmosphere by oil gas in the process of oil extraction established.

In the third zone, where oil extraction started at the end of the XX century, well-functioning, innovative, environmentally friendly technologies were accomplished, and this allowed to avoid disturbance of the balance in components of ecological system.

All this is proved by the results of research of components of ecological system in three conditionally divided territories of oil extraction by averaging of data of quality of life environment over a period of 2007-2012. At that the method of conversion of indicators of quality of air, water and soil with different dimension into points is used, and this allowed to obtain generalized parameters of 24 indicators which characterize the level of pollution of air, water and soil of three conditional zones. Later on these figures were used in the process of model development of the index of population welfare in different municipal districts of the Republic of Tatarstan.

Thus, on the basis of complex multidimensional research several blocks of factors with great influence on quality of life and health of population or index of population welfare were singled out in order to determine quantitatively measured indicative parameters of quality of life, health, welfare of population:

- Medical-demographic parameters;

- Standard of living;

- Social sphere;

- Consumer market of goods and services;

- Labor sphere;

- Supply of housing per capita to the population;

- Supply of transportation and communication facilities to the population ;

- Crime rate (Safety level);

- Environmental condition. 
On the basis of the research 27 indicative parameters were set for quantitative estimate of the index of population welfare for every block of factors. Choice of parameters for development of integral index of population welfare was made from the available statistical base [1;10]. In the developed system of parameters there are no expert indicators and indicators based on the results of population survey.

Empirical approach, with the well-known in statistics the index merge technique method of parameters of different dimensions was introduced to solve problems concerning comparison of the above-mentioned characteristics of municipal districts. This method allowed to calculate the complex integrated parameter "index of population welfare". The index of population welfare covers such parameters as the level of social-economic development, personal income, cost of living, quality of medical service, education, environmental condition, safety, cultural level, level of small and medium enterprise development, etc.

In the result, the final index of population welfare $\left(I_{R}\right)$ of this or that administrative unit as the index characterizing the level and quality of life of regional population will be characterized by the sum of values of chosen by us index scores:

$I_{R}=\sum_{i=1}^{N} P_{i},(1)$

where $i$ - index;

$N$ - number of indexes in the set;

$P_{i}$ - score which corresponds to the value of the $i$-index.

This formula can be used for calculation of the index of the group of parameters which characterize the condition of regional population in some aspect, for example, concerning the level of environmental pollution. In this case the set of indexes will include only this aspect of the problem.

According to the above-mentioned methodology, the authors of the work performed calculations in 22 municipal regions of the Republic of Tatarstan; they allowed to rank the regions of the republic according to social-economic conditions and favorable living environment (table 1).

Table 1: Values and rating of welfare index of municipal districts on the Republic of Tatarstan (2012)

\begin{tabular}{|l|c|c|}
\hline Municipal districts (MD) & Index of population welfare, points & Rank of MD \\
\hline 1 zone & & \\
\hline Aznakayevsky & 51 & 4 \\
\hline Almetyevsky & 80 & 1 \\
\hline Bavlinsky & 49 & 7 \\
\hline Bugulminsky & 48 & 8 \\
\hline Leninogorsky & 51 & 4 \\
\hline Cheremshansky & 45 & 11 \\
\hline Yutazinsky & 28 & 22 \\
\hline 2 zone & & 16 \\
\hline Aksubayevsky & 33 & 4 \\
\hline Yelabuzhsky & 51 & 14 \\
\hline Zainsky & 36 & 2 \\
\hline Muslyumovsky & 65 & 9 \\
\hline Novosheshminsky & 47 & 18 \\
\hline Nurlatsky & 32 & 18 \\
\hline Sarmanovsky & 32 & 14 \\
\hline 3 zone & & 3 \\
\hline Agryzsky & 36 & 10 \\
\hline Aktanyshsky & 58 & 13 \\
\hline Alekseevsky & 46 & 12 \\
\hline Alkeevsky & 38 & 16 \\
\hline Mendeleevsky & 43 & 18 \\
\hline Menzelinsky & 33 & 21 \\
\hline Mamadyshsky & 32 & \\
\hline Chistopolsky & 30 & \\
\hline & & \\
\hline
\end{tabular}

\section{Results}

In the result of the research it was found that the maximum or the most optimal index of population welfare is in the 
Almetyevsky (80 points), Muslyumovsky (65 points) and Aktanyshsky (58 points) municipal districts which belong to different zones but which are the leaders in their regions. Without any doubt, in these regions the index of population welfare greatly correlates with the level of social-economic development of the municipal district $(p<0,05)$, i.e. the higher the Gross Regional Product and the average income of the population are, the higher the index of population welfare is, despite heavy ecological loading in the regions of the first group. But in the majority of regions of this conditional zone the costs for environmental protection measures, for public health service per capita are rather high (pic.1, 2) (made according to [1]).

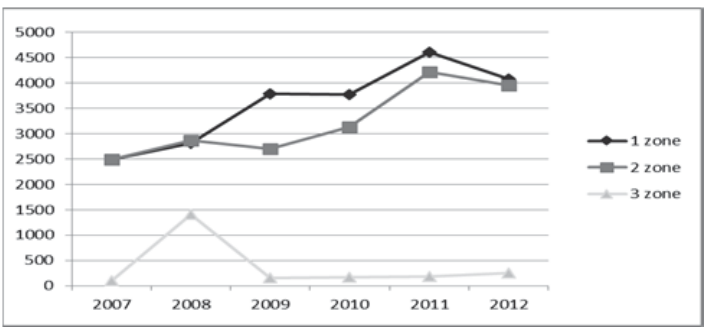

Pic. 1. Dynamics of costs for environmental protection per capita of the municipal districts of the Republic of Tatarstan of 3 conditional zones for 2007-2012, roubles

Effective social-economic policy in these regions promoted and supported high index values.

The Chistopolsky (30 points) and Yutazinsky (28 points) municipal districts have comparatively low ratings; the rating of the other three districts - the Nurlatsky, Sarmanovsky and Mamadyshsky - is a little bit better (32 points each). Although they belong to the regions of much more later oil recovery development (except the Yutazinsky district which belongs - according to the present methodology - to the $1^{\text {st }}$ conditional zone), and, how it has already been said, contemporary environmentally friendly technologies are used in these districts, but the value of the index of population welfare in these districts is characterized as raising fears. In these districts expenses for public health care per capita grow annually and these expenses in all conditional zones are approximately on the same level (pic. 2).

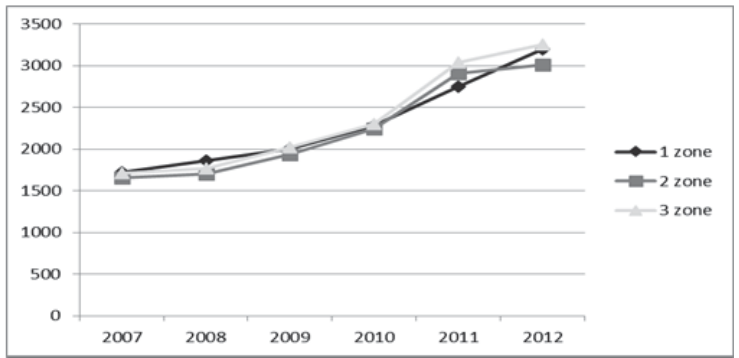

Pic. 2. Dynamics of costs for public health service per capita of the municipal districts of the Republic of Tatarstan of 3 conditional zones for 2007-2012, roubles

\section{Conclusions}

Multidimensional indexes, as a rule, are affected by a lot of differently directed factors, that is why such negative factors as high death rate, including the infantile one, increased crime rate, insufficiently high quality of education in comparison with the other subjects played important role in the researched regions. The administration of the above-mentioned districts should pay attention to these factors and indicators which form the index of population welfare.

The boundaries of the human living environment are expanding, interaction of society and nature is constantly growing, and all this inevitably causes increased scope of degradation of natural environment. In order to minimize negative influence on the environment it's necessary to study every subsystem as independent part of the system, which is the subject of research, forecast and planning. But it's always necessary to keep in mind that their many-sided living activities and complete fulfilment of inner potencies are possible only in case of integration and dialectic unity of these 
systems. That's why multidimensional research and complex social-economic forecast are especially important.

In our opinion, studies of the index of population welfare in dynamics is reasonably necessary together with the statistical analysis of ratings of the territories. This index is able to provide data concerning real situation in these districts. Later on it will allow to monitor and control figures of social-economic development of these subjects in time aspect, to estimate effectiveness of social-economic policy of governing authorities in municipal territorial districts for definite time intervals.

\section{Acknowledgements}

Publication is prepared in the frames of the project № 13-12-16009 supported by Russian Humanitarian Science Foundation.

\section{References}

Glebova I.S., Sadyrtdinov R. and Rodnyansky D. Impact Analysis of Investment Attractiveness of the Republic of Tatarstan on Fixed Investments of its Leading Companies // World Applied Sciences Journal 26 (7): 911-916, 2013.

Bagautdinova N.G, Safiullin L.N, Badrtdinov N.N The Role of Consumer Expenses in Ensuring Forward Dynamics of The Russian Economy/l Mediterranean Journal of Social Sciences.- Vol.5, No12, (2014)-pp.43-48.

Costanza R., Fisher B., Ali S., Beer C. 2007. Quality of life: An approach integrating opportunities, human needs, and subjective wellbeing/ Ecological Economics Nolume 61, Issues 2-3, pages 267-276.

Fakhrutdinova, E., Safina, L., Kolesnikova, J., Fedor, Mikhailov. Quality formation of working life of the youth// World Applied Sciences Journal. Volume 27, Issue 13, 2013, Pages 87-91.

Bagautdinova N.G., Safiullin L.N., Minnahmetov R.R. Institutionalization of Firm Environment in Conditions of Growing Turbulence/l Mediterranean Journal of Social Sciences.- Vol.5, No12, (2014)-pp.55-58.

Discoli C., Martini I., San Juan G., Barbero D., Dicroce L., Ferreyro C., Esparza J. 2014. Methodology aimed at evaluating urban life quality levels. Sustainable Cities and Society / Volume 10, pages 140-148.

Safiullin, M.R., Elshin, L.A., Prygunova, M.I., Galyavov, A.A. (2013). Complex Analysis of Prospects of the Volga Federal District Regions Development: Methodology and Practice. World Applied Sciences Journal 27, 4, 508-511.

Bagautdinova B.G., Sarkin A.V, Khadiullina G.N., Averyanov B.A., Arzhantseva N. Development of Paternalistic Strategy of Industrial Growth with Regard to Institutional Traps (Qwerty- Effects)// Mediterranean Journal of Social Sciences.- Vol.5, No12, (2014)pp.49-54.

Ferriss, A.L. 1988. The uses of social indicators. Social Forces, 66, pages 601-617.

Kirshin I.A., Datsyk A.A., Titov A.V. Forecasting the Dynamics of an Innovative Cycle. - World Applied Sciences Journal (Economics, Management and Finance). - 2013. - №27. - P. 197 - 201.

Kopmann A., Rehdanz K.2013. A human well-being approach for assessing the value of natural land areas. Ecological Economics. Volume 93 , pages 20-33.

Malkina-Pykh I., Pykh Y. 2008. Quality-of-life indicators at different scales: Theoretical background. Ecological Indicators / Volume 8, Issue 6, pages 854-862.

Bagautdinova N.G., Safiullin L.N., Mubarakov I.A. The Role of Quality of Goods in Formation of Consumer Choicel/ Mediterranean Journal of Social Sciences.- Vol.5, No12, (2014)-pp.63-68.

Safiullin L.N., Gafurov I.R., Shaidullin R.N., Safiullin N.Z. Socio-economic development of the region and its historical and cultural heritage. Life Science Journal 2014; 11(6s): 400-404.

Moser G. 2009. Quality of life and sustainability: Toward person-environment congruity/ Journal of Environmental Psychology Volume 29, Issue 3, Pages 351-357

Venkatachalam L. 2007. Environmental economics and ecological economics: Where they can converge? /Ecological Economics Volume 61 , Issues 2-3, pages 550-558 
